\title{
(Po)éticas da escrevivência
}

Luana Barossi ${ }^{1}$

O que eu tenho pontuado é isso: é o direito da escrita e da leitura que o povo pede, que o povo demanda. É um direito de qualquer um, escrevendo ou não segundo as normas cultas da língua. É um direito que as pessoas também querem exercer.

Conceição Evaristo

Eu disse: o meu sonho é escrever! Responde o branco: ela é louca. O que as negras devem fazer...

É ir pro tanque lavar roupa.

Carolina Maria de Jesus

A declaração de Evaristo e o poema de Carolina Maria de Jesus que inauguram este ensaio indicam a urgência de abertura dos estudos literários a enunciações que se mantiveram fora do que chamamos de cânone, uma vez que vêm de espaços historicamente silenciados e marcados por resquícios ainda presentes, na contemporaneidade, do colonialismo e da escravidão. Essa abertura tem ocorrido aos poucos, pois a reivindicação do direito à escritura - e à escrevivência - parece ter sido ouvida tardiamente. Uma ilustração dessa extemporaneidade é o caso de Carolina Maria de Jesus. Apesar do sucesso de vendas de Quarto de despejo à época da publicação, a crítica passou a valorizar a obra da autora como uma produção digna de ser estudada como literatura muito recentemente. Outros exemplos são as produções contemporâneas de Conceição Evaristo e Jarid Arraes, que, apesar de bastante aclamadas por uma crítica ávida pela revisão do cânone, são de difícil acesso ou pouco divulgadas pela mídia hegemônica.

Felizmente, como aponta Boaventura Sousa Santos (1997), há, paralelamente ao processo capitalista que promove a manutenção dos silenciamentos históricos, um movimento de globalização contrahegemônica. A globalização implica, de acordo com o autor, conjuntos

\footnotetext{
${ }^{1}$ Doutora em estudos comparados de literaturas de língua portuguesa e professora da Universidade da Integração Internacional da Lusofonia Afro-Brasileira (Unilab), Redenção, Ceará, Brasil. Email: luanabarossi@unilab.edu.br
} 
diferenciados de relações sociais, sendo que a globalização contrahegemônica constitui, resumidamente, a apropriação, por parte dos indivíduos advindos dos locais de enunciação marginalizados, dos meios da inevitável globalização inspirada pelos processos neoimperialistas contemporâneos, em movimento de "globalização de baixo para cima" (1997, p. 112), o que pode inspirar também estratégias de desconstrução, na contemporaneidade, dos discursos que instituem relações de poder pautadas nas violências (físicas e epistêmicas) dos processos colonialistas.

O conceito de globalização contra-hegemônica é importante como sinal de resistência em um tempo marcado por uma retomada de valores reacionários que Antonio Candido já havia tido como parcialmente abolidos quando escreveu seu texto $O$ direito à literatura, em 1988, ano da promulgação da Constituição brasileira: "hoje não se afirma com a mesma tranquilidade do meu tempo de menino que haver pobres é a vontade de Deus, que eles não têm as mesmas necessidades dos abastados, que os empregados domésticos não precisam descansar, que só morre de fome quem for vadio" (Candido, 1988, p. 171). No mesmo texto, Candido ressalta o valor do texto literário erudito como um direito de todos, por ser um "bem incompressível", isto é, essencial à vida. Por outro lado, parece fugir ao escopo do autor naquele momento a discussão acerca do valor literário das produções de fora do circuito intelectual erudito, como se o sujeito subalternizado ${ }^{2}$ tivesse direito à leitura, mas não à escritura, uma vez que suas produções não poderiam adentrar no Olimpo reservado às altas literaturas.

Dessa forma, neste texto, procuro traçar um diálogo entre o pensamento de Antonio Candido (1988), Gayatri Spivak (1985) e Homi Bhabha (2014) e o conceito de escrevivência, de Conceição Evaristo (2008). Tal diálogo permite pensarmos na ética em duas dimensões: a primeira é a da crítica, em termos de responsabilidade por abrir espaços às produções literárias antes obliteradas; e a segunda é a noção de escrevivência, instituída pela potência da escritura (po)ética de novas maneiras de existir que não aquelas instituídas pelo histórico escravagista e colonial, mas buscando a criação de um campo simbólico que entrelaça história, memória e experiência.

\footnotetext{
${ }^{2}$ Escrevo "subalternizado" no lugar de "subalterno" como uma escolha ponderada, uma vez que um sujeito não escolhe ter essa posição na estrutura social.
} 
Ressalto que o conceito de ética adotado neste artigo aproxima-se do desenvolvido por Gilles Deleuze em diálogo com Spinoza, bem como as considerações de Michel Foucault em diálogo com Friedrich Nietsche sobre a criação de novos modos de vida ou da vida como obra de arte. Deleuze intersecciona essas noções:

Não se trata mais de formas determinadas, como no saber, nem de regras coercitivas, como no poder: trata-se de regras facultativas que produzem a existência como obra de arte, regras ao mesmo tempo éticas e estéticas que constituem modos de existência ou estilos de vida (mesmo o suicídio faz parte delas). É o que Nietzsche descobria como a operação artista da vontade de potência (Deleuze, 1992, p. 123).

Essas regras éticas e estéticas que constituem modos de existência, quando despregadas das formas determinadas do saber e coercitivas do poder (Foucault, 1979), trazem a possibilidade de escapar aos próprios pressupostos críticos que elaboram cânones ou seleções que servem como recurso de manutenção de relações de poder historicamente instituídas. Nesse sentido, o campo literário assume uma dimensão distinta, não determinada pelo aspecto coercitivo.

Antonio Candido faz uma importante relação entre a literatura e os direitos humanos, ao colocar aquela no patamar dos "bens incompressíveis", aqueles que não podem ser negados a ninguém, uma vez que assume um importante papel de humanização. Há uma tendência, dentro das classes privilegiadas da sociedade, de pensar que os indivíduos alocados historicamente numa posição de subalternidade devem ter como direitos iguais apenas o necessário para a sobrevivência. Ao colocar a literatura nesse patamar (de necessária à sobrevivência), Candido a estabelece retoricamente como uma necessidade básica do ser humano. Para tanto, o autor propõe a relação da literatura com os direitos humanos por dois ângulos diferentes: o primeiro diz respeito à organização mental que ela proporciona, porque ao "dar forma aos sentimentos e à visão do mundo ela nos organiza, nos liberta do caos e portanto nos humaniza"; o segundo é por seu aspecto de desmascaramento social e denúncia, pelo fato de "focalizar as situações de restrição dos direitos, ou de negação deles, como a miséria, a servidão, a mutilação espiritual" (Candido, 1988, p. 186). Contudo, Candido não estabelece uma terceira dimensão, que não diz respeito ao direito àquela literatura erudita que narra o subalternizado do ponto de 
vista do intelectual, mas a literatura produzida e narrada pelo próprio subalternizado.

Em Quarto de despejo, Carolina Maria de Jesus, depois de relatar um dia extremamente exaustivo como catadora de papel, escreve: "O nervoso interior que eu sentia ausentou-se. Aproveitei a minha calma interior para eu ler" (Jesus, 1993, p. 10). Ela não apenas lê - inclusive aqueles livros da chamada alta literatura, que teriam, de acordo com Candido, um papel humanizador -, como narra seu próprio ato de leitura:

Fui catar papel, mas estava indisposta. Vim embora porque o frio era demais. Quando cheguei em casa era 22,30. Liguei o radio. Tomei banho. Esquentei comida. Li um pouco. Não sei dormir sem ler. Gosto de manusear um livro. O livro é a melhor invenção do homem (Jesus, 1993, p. 22). ${ }^{3}$

Ao estabelecer a importância do "pobre como temário do romance", que serviria para a "onda de desmascaramento social" como meio de "expor e denunciar a miséria" (Candido, 1988, p. 184 e 185) e, ao mesmo tempo, estabelecer uma zona abissal entre o que chamou de "cultura popular" e "cultura erudita", Candido ainda não expõe o papel humanizador também da escritura, pois hierarquiza os saberes. A produção poética popular já seria, então, de antemão, um "Outro" a ser civilizado. Além de ser personagem, "o pobre" pode também ser autor e mostrar a perspectiva de quem de fato vive as circunstâncias narradas, bem como seus anseios e desejos, como Carolina de Jesus denuncia nesse trecho de Quarto de despejo: "Vou escrever um livro referente a favela. Hei de citar tudo que aqui se passa. E tudo que vocês me fazem. Eu quero escrever o livro, e vocês com estas cenas desagradaveis me fornece os argumentos" (Jesus, 1993, p. 17).

A afirmação de Candido (1988, p. 188), de que “o pressuposto é que todos devem ter a possibilidade de passar dos níveis populares aos níveis eruditos como consequência normal da transformação de estrutura", traz a importante reflexão do direito de todos à literatura, mas já estabelece de antemão um lugar de subalternidade ao que ele chama de "níveis populares", além de ocultar a propagação da problemática contida na questão fundadora da obra de Gayatri Spivak: além de ler, "pode o subalterno falar?"

\footnotetext{
${ }^{3}$ A grafia original do texto de Carolina Maria de Jesus foi respeitada nas citações deste artigo.
} 
O teórico italiano Antônio Gramsci elabora, nos Cadernos do cárcere, escritos entre 1929 e 1937, quando estava na prisão, a noção de "classes subalternas", partindo de uma abordagem marxista. Suas considerações consistiam na categorização dessas classes e na tese de que elas seriam constituídas por um conjunto de indivíduos alijados do poder, de forma que deveriam adquirir a consciência de classe e a unificação para caminhar em direção à emancipação. Essa emancipação do sujeito subalterno supõe também a emancipação cultural e a percepção de que os campos econômicos, políticos e filosóficos são expressão de uma mesma realidade em movimento. O movimento passaria, então, pela construção de um novo bloco histórico e, como constitutiva deste processo, por uma reforma moral e intelectual. Seu conceito foi utilizado, reformulado e criticado por inúmeros intelectuais, mas talvez o trabalho mais emblemático que dialogue com o conceito deslocando-o a uma nova dimensão seja o ensaio Pode o subalterno falar?, da indiana Gayatri Spivak, publicado pela primeira vez em 1985.

A perspectiva universalizante de Gramsci é criticada por Spivak, que acredita que o sujeito subalterno não ocupa e nem pode ocupar uma categoria monolítica, mas eminentemente heterogênea, de maneira que propor uma unificação de sua fala já seria, por si só, seu apagamento ou a manutenção de seu silenciamento histórico. Para a autora, a subalternidade diz respeito às classes mais baixas da sociedade em termos de modos específicos de exclusão dos mercados da representação política e legal. Os pontos cruciais no ensaio são, a nosso ver, três: i) a demonstração da posição do sujeito subalterno sexuado (a mulher); ii) o deslocamento da análise do "Outro" a partir do conjunto de codificações epistêmicas dominantes para o contexto específico de que seus exemplos tratam; e iii) a responsabilidade institucional do crítico (ou, mais especificamente, da crítica) contemporâneo para com essa questão que nomeia o artigo: pode o subalterno verdadeiramente falar?

Apesar da crítica a autores como Gilles Deleuze e Michel Foucault, a autora lança mão do mesmo desafio proposto por eles em parte de suas obras: questionar as históricas violências (tanto físicas e psicológicas, quanto epistêmicas) da sociedade chamada de "ocidental" para com o sujeito colonizado ou marginalizado socialmente, alocado na posição de "Outro" por excelência, sempre em função do "Mesmo", sendo que o Mesmo é aquele que supostamente detém o conhecimento científico, universal e verdadeiro, ou seja, o conjunto de normas, costumes e 
codificações dessa "sociedade ocidental". A diferença da proposta de Spivak para a dos filósofos criticados por ela reside no fato de que, enquanto eles procuraram buscar uma história alternativa e não hegemônica (dar voz aos loucos, aos presos, aos marginalizados socialmente), ela alega que é necessário reler a história como foi escrita pela perspectiva dominante (tradicional e colonialista) de forma a determinar estratégias de desconstrução e só então "oferecer um relato de como uma explicação e uma narrativa da realidade foram estabelecidas como normativas" (Spivak, 2010, p. 48). Pois, de acordo com a autora, é necessário penetrar na codificação que produz a violência epistêmica para compreender (e desconstruir) seu projeto.

O texto de Spivak tem como ponto de partida a denúncia de algumas questões referentes ao projeto colonial britânico na Índia e suas intervenções na estruturação da sociedade local, bem como a criação, por meio desse processo, de uma visão "ocidental" da sociedade indiana, extremamente estereotipada e unificadora. Algumas das considerações de Spivak se aproximam da noção de "Orientalismo" como proposta por Edward Said: um conjunto de noções do Oriente (Outro) em função do Ocidente (Mesmo). Boaventura de Sousa Santos amplia essa perspectiva e propõe uma dupla dicotomia nessa construção de alteridade, ao trazer à luz o processo histórico de marginalização do Sul, que, assim como o Oriente, assume uma posição periférica com relação à epistemologia de matriz europeia. O Oriente seria então o Outro do Ocidente, enquanto o Sul seria o Outro do Norte. Santos consegue, assim, incluir vozes historicamente silenciadas com seu projeto "Epistemologias do Sul".

Uma dialética com relação à produção dos intelectuais que estudam a subalternidade é construída por Spivak quando a autora considera a importância desses estudos, mas ao mesmo tempo os critica por partirem, como Gramsci, de uma visão monolítica da "classe subalterna". Há classes intermediárias, propõe a autora, além de indivíduos que, mesmo dentro dos espaços que seriam "classificados" como subalternos, ainda assim não têm lugar de fala: são os subalternos dos subalternos, como é o lócus da mulher em determinado contexto de subalternidade.

A partir dessas considerações, surge a colocação mais significativa no contexto do entendimento geral que se viria a ter da obra da autora, citação esta que será retomada ao final do presente artigo: 
No contexto do itinerário obliterado do sujeito subalterno, o caminho da diferença sexual é duplamente obliterado. A questão não é a da participação feminina na insurgência ou das regras básicas da divisão sexual do trabalho, pois, em ambos os casos, há "evidência". É mais uma questão de que apesar de ambos serem objetos da historiografia colonialista e sujeitos da insurgência, a construção ideológica de gênero mantém a dominação masculina. Se no contexto da produção colonial, o sujeito subalterno não tem história e não pode falar, o sujeito subalterno feminino está ainda mais profundamente na obscuridade (Spivak, 2010, p. 66-67).

O terceiro mundo ou, como propõe Spivak, a noção de "terceiromundismo", é uma versão contemporânea (considerando que o texto foi escrito em 1985) do colonialismo, que serve para justificar a divisão internacional do trabalho, da mesma forma que os colonizadores usavam a narrativa da "civilização" de povos tidos por eles como primitivos para justificar toda a violência do processo colonizatório. A manutenção, como discurso dominante, da noção de "Outro" (terceiro mundo) de modo estereotipado é bastante útil - para os que desejam manter a perspectiva dominante como norma - na manutenção do controle e da posição hegemônica. O Outro não fala e, se falar, tem seu discurso reduzido, de antemão, à perspectiva de que é "inferior" porque não parte do mesmo conjunto de normas e codificações do "Mesmo". Isso é o que acontece com o esforço editorial de reduzir a escritura de Carolina de Jesus, por exemplo, a mero documento sociológico, perceptível no próprio subtítulo "diário de uma favelada".

Para Spivak, a estratégia para reverter esse quadro historicamente estabelecido não pode ser desenvolvida sem uma postura (auto)crítica. Desta forma, os intelectuais passam por um processo de questionamento de suas posições em três dimensões sucessivas: primeiro por obliterar a fala do sujeito historicamente subalternizado; segundo por "falar por" grupos historicamente marginalizados, partindo de sua perspectiva privilegiada; e terceiro por alegar que o subalterno deve falar por si, sem considerar que, mesmo que tentasse falar, não seria ouvido, uma vez que não detém o espaço privilegiado de fala e tampouco o conjunto de normas socialmente construídas que fariam com que fosse escutado. A estratégia de escape a essa problemática como oferecida por Spivak entra em consonância com a gramatologia derridiana. $\mathrm{O}$ intelectual não pode falar pelo subalterno, mas "o espaço em branco inscrito no texto" 
(Spivak, 2010, p. 123) deve ser confiado ao "Outro" da história. Ou seja, o espaço deve ser aberto para que ele fale.

Esse espaço em branco do texto, noção emprestada de Jacques Derrida, só pode ser produzido por meio de uma leitura da história até então relatada com um questionamento sobre as posições e as relações de força estabelecidas no discurso que formam o campo epistemológico a ser analisado. Para tanto, Spivak oferece dois exemplos bastante emblemáticos da posição da mulher indiana: o ritual das viúvas Sati e o suicídio de Bhuvaneswari Bhaduri, bem como as narrativas construídas sobre esses acontecimentos.

As viúvas Sati subiam nas piras funerárias de seus maridos e praticavam a autoimolação ou, como ficou conhecido no ocidente, "o sacrifício das viúvas". Os colonizadores britânicos extinguiram a existência do ritual, com o discurso de que estavam salvando as mulheres indianas de seu subdesenvolvimento cultural. Essa abolição ficou sendo conhecida como "homens de pele clara salvam mulheres de pele escura de homens de pele escura", partindo do pressuposto que os "homens de pele escura" haviam determinado a existência do ritual. A segunda (e oposta) narrativa sobre as viúvas Sati foi a consideração de que as mulheres eram heroínas e queriam realmente morrer para acompanhar seus falecidos esposos.

O papel do intelectual, nesse caso, é perguntar: "o que significa isso?". É necessário pesquisar o conjunto de códigos culturais envolvidos no ritual para que seja possível desconstruir os estereótipos criados sobre ele tanto pelos britânicos, quanto pelos intelectuais que tentaram estudar os acontecimentos por meio da epistemologia de matriz "Ocidental", "do Norte" ou do "Primeiro Mundo".

As Sati eram encorajadas a cometer suicídio como uma "demonstração de coragem" e de "força de caráter". Em algumas regiões da Índia, as viúvas tinham a possibilidade de herdar as terras do marido após sua morte, o que faria com que chegássemos à conclusão precipitada de que eram encorajadas a se suicidar para que não herdassem as terras. No entanto, essa outra narrativa construída sobre o ritual desconsiderava que as mulheres viviam sob um regime chamado de avarudda stri, termo que, se traduzido ao português, significaria algo próximo de "mulher encarcerada", o que é suficiente para oferecer uma breve noção das condições de vida das herdeiras do ritual Sati. Nas escrituras brâmanes consta que, uma vez queimadas no fogo funerário de 
seus maridos, as mulheres matariam definitivamente seu corpo feminino "em todo ciclo do nascimento", o que significava que nunca mais reencarnariam como mulheres. Num contexto em que ser mulher equivalia a não poder falar e ser uma prisioneira, a ênfase no livre arbítrio - "elas se matam porque querem" - estabelece o peculiar infortúnio de se ter um corpo feminino. Ao considerar essas narrativas mais específicas, Spivak enaltece esse não lugar de fala do subalterno e, mais especificamente, da mulher subalterna, de modo que a intelectual contemporânea tem o papel de buscar esses elementos da história para ao menos trazer à luz esses interstícios, mostrar "o que estava em branco no texto" ou, em outras palavras, o que foi historicamente silenciado.

O último exemplo de Spivak trata da história de Bhuvaneswari Bhaduri, uma menina de 16 anos que se enforcou no apartamento do pai em Calcutá, em 1926. Algumas das (poucas) notícias sobre o acontecimento propuseram que ela havia se matado por amor ou por uma gravidez indesejada, desconsiderando o fato de que ela havia esperado o período menstrual para o ato, precisamente para evitar esse discurso. Após uma pesquisa bastante complexa, Spivak descobre que Bhuvaneswari havia se envolvido com um movimento pela libertação da Índia e havia recebido dos líderes do movimento a incumbência de um assassinato político. Impossibilitada de recusar e de falar, ela espera a menstruação, numa inversão da interdição das viúvas Sati (que não podiam praticar a autoimolação em período menstrual), para reivindicar seu "privilégio", abandonar seu corpo silenciado. Spivak ressalta que, nesse ponto de vista, o suicídio de Bhuvaneswari é uma reescrita subalterna - não empática - do texto social do suicídio Sati, pois a menina reivindica o "privilégio" de abandonar seu corpo feminino, ao mesmo tempo em que subverte o ritual historicamente construído que considerava "impura" a mulher em período menstrual.

Apesar da conclusão nada otimista do ensaio de Spivak, de que o subalterno "não pode falar", a autora ressalta que a intelectual (especialmente a intelectual mulher) tem um desafio que "não deve rejeitar com um floreio" (Spivak, 2010, p. 136), que é trazer à luz as narrativas historicamente alocadas numa posição de subalternidade e procurar compreender seu lócus de enunciação ou, ao menos, manter os "espaços em branco inscritos no texto" para que suas vozes possam soar. Essa reescrita da história das Sati e de Bhaduri é o ato ético da intelectual de abrir espaços onde antes não havia para que a memória 
possa soar na história, o que se aproxima do conceito de escrevivência, de Conceição Evaristo.

Embora Antonio Candido tenha proposto que o sistema literário brasileiro fora instituído há bastante tempo, tendo como um de seus momentos formativos a produção literária do século XIX com seu projeto nacionalista, os cânones nacionais abordam o sujeito subalternizado sempre como personagem, dificilmente incluindo no panteão obras de autoria "subalterna". Podemos traçar um paralelo dos estudos de Spivak com uma série de intelectuais brasileiras que já fazem uso das práticas sugeridas pela indiana, ao estudarem narrativas subalternas ad hoc ou relidas, como é o caso dos inúmeros estudos sobre a obra de Carolina Maria de Jesus, com destaque para Quarto de despejo. Nessa obra, a autora, negra, moradora da favela do Canindé, na zona norte de São Paulo, expressa seu lócus de enunciação por meio de diários que expunham sua posição de subalternidade. A noção de que sua posição social correspondia a um "quarto de despejo" pode ser lida como a percepção da posição dos sujeitos marginalizados pelo processo colonial/imperialista (tanto stricto sensu, quanto pelo neocolonialismo epistêmico denunciado por Spivak e Edward Said), que realmente não têm lugar de fala nos espaços hegemônicos.

Nesse sentido, as palavras de Homi Bhabha sobre o direito de narrar emergem como a colocação da possibilidade, na contemporaneidade, da reversão da posição subalterna por meio da narrativa, um desejo "de, por um direito coletivo e ético, à diferença na igualdade" (Bhabha, 2014, s.p., tradução nossa). $\mathrm{O}$ autor alega que as sociedades que viram suas costas ao direito de narrar são sociedades de um silêncio ensurdecedor, tais quais as nações autoritárias, estados policiais e culturas xenofóbicas. "Permitir que tais muros de silêncio sejam construídos no nosso meio e em nossas mentes é viver em suas sombras muito depois de eles terem sido derrubados", escreve Bhabha (2014, s.p., tradução nossa).

Uma alegação comum por parte de intelectuais dos estudos literários é que as possíveis produções literárias de sujeitos subalternizados ou de baixa escolaridade não conteriam o que é necessário para serem consideradas grandes obras, por não terem um cuidado com a forma, serem desprovidas de uma poética, de uma literariedade e se restringirem ao que é panfletário. Essas rasas considerações nada têm de inócuas, pois perpetuam as estruturas de poder hegemônico no campo dos estudos literários e esperam que a poética seja filiada de uma única 
tradição. Lembremos aqui das colocações de Octavio Paz em $O$ arco e a lira: "um quadro, uma escultura, uma dança são, a sua maneira, poemas" (Paz, 2014, p. 26). Isso porque a literatura não se reduz à forma nem deve ser classificada unicamente por ela. Um soneto, diz Paz (2014, p. 22), "não é um poema, e sim uma forma literária, exceto quando esse mecanismo retórico - estrofes, metros e rimas - foi tocado pela poesia". Dessa forma, qualquer produção, seja ela um poema, uma narrativa ou uma obra de autoficção, pode ser tocada pela poesia.

Classificar a obra caroliniana como documento sociológico, como foi por tanto tempo (Miranda, 2013), é uma estratégia de silenciamento que segue os mesmos pressupostos daqueles aplicados nas narrativas criadas sobre a morte de Bhuvaneswari Baduri: contar sua história como se fosse um suicídio em decorrência de um amor não correspondido faz com que sua narrativa seja reduzida aos estereótipos esperados socialmente para uma narrativa feminina, mantendo seu "não lugar" de fala e impedindo que ela conte a própria história. No caso específico de Carolina, classificá-la como mero documento sociológico corresponde a reduzir sua escritura ao que se espera socialmente de uma mulher negra, habitante da favela.

A pouca divulgação de autoras contemporâneas como as brasileiras Jarid Arraes e Conceição Evaristo ${ }^{4}$ assim como a dificuldade de se encontrar as obras de autoras como a cabo-verdiana Dina Salústio e a moçambicana Paulina Chiziane, também são indicadores dessa estratégia de silenciamento. Os pesquisadores dos estudos literários têm, nesse sentido, uma responsabilidade ética para que esse quadro possa ser alterado. O conceito de escrevivência de Evaristo (2008) tem a potência de colocar em relevo essas narrativas antes desconsideradas, como veremos a seguir.

A história oficial é baseada em uma perspectiva essencialmente colonialista, configurando o que chamo aqui de intracolonialismo epistêmico, pois lança mão de termos como "descobrimento", "primitivo" e "civilizado", conceitos esses que passaram a fazer parte da imaginação constituinte de um grupo significativo de pessoas, afinal, é essa a terminologia ensinada nas escolas tradicionais. Crescemos ouvindo que

\footnotetext{
${ }^{4}$ Em que pese a obra Olhos d'água, de Conceição Evaristo, ter conquistado a terceira posição na categoria contos do prêmio Jabuti em 2015.
} 
esse território onde habitamos foi "descoberto". Questionar essa noção faz com que contestemos também a constituição do nosso "passado" oficial.

Edward Said, na introdução a Cultura e imperialismo, examina a maneira pela qual os processos imperialistas ocorreram além do plano das leis econômicas e das decisões políticas, e - por predisposição, pela autoridade de formações culturais identificáveis, pela consolidação contínua na educação, literatura, artes visuais e musicais - manifestaramse em outro nível de grande importância, o da cultura nacional, que em geral é apresentada como algo asséptico, um campo de monumentos intelectuais imutáveis, livre de filiações mundanas (Said, 1995, p. 47).

A partir de um diálogo com T. S. Elliot, Said conclui que a invocação do passado constitui uma das estratégias mais comuns nas interpretações do presente. O que inspira tais apelos não é apenas a divergência quanto ao que ocorreu no passado e o que teria sido esse passado, mas também a incerteza se o passado é de fato passado ou se persiste, mesmo que sob outras formas. Isso significa que, mesmo que compreendamos os fatos históricos em seu sentido cronológico, ou seja, algo que já passou, não há nenhuma maneira de isolar o passado do presente, pois ambos se modelam mutuamente, um inclui o outro. Isso significa a imanência de uma mudança de olhar. Se pensarmos no "descobrimento" do Brasil sob a perspectiva dos indígenas (aimorés, tupiniquins, tupinambás etc.) que habitavam a costa do território hoje chamado Brasil à chegada dos portugueses, esse fato histórico não se configuraria como descobrimento. A noção propagada de descobrimento faz parte da perspectiva colonialista e imperialista. Um problema que podemos encontrar para a reescrita dessa história sob outras perspectivas é a ausência de documentos oficiais "do outro lado", que permitam a tal globalização contra-hegemônica defendida por Santos. A questão é que, em geral, a perspectiva colonialista/imperialista que persiste no imaginário coletivo desconsidera as produções discursivas de fora de seus espaços institucionais, em especial quando essas produções têm como único documento a memória transmitida pela tradição oral. Daí a necessidade de se abrir espaços no texto para esses discursos. ${ }^{5}$

Ao trazer um questionamento à história oficial e constituir a memória e a criação poética como reescritas dessas histórias obliteradas, a noção de

\footnotetext{
${ }^{5} \mathrm{O}$ presente artigo trata mais especificamente de produções do contexto afro-brasileiro, mas é necessário, também, que se abra (mais) espaço para as produções indígenas.
} 
escrevivência age como instância ética, estética e poética, pois dá vazão à mudança de perspectiva por meio do processo criativo. $\mathrm{O}$ sujeito autoral que se inscreve no texto, como é o caso de Quarto de despejo, de Carolina de Jesus, e as narrativas discordantes das histórias oficiais, como é o caso de As lendas de Dandara, de Jarid Arraes, amalgamam-se na constituição de universos de significados e sistemas simbólicos alternativos, possibilitando novos olhares para os acontecimentos ou, ainda, a própria criação, no sentido ético, de novas maneiras de existir.

Nos entremeios de sua narrativa poética, Carolina de Jesus reivindica seu lugar de pertença à literatura e denuncia a posição na qual foi alocada: uma posição marginal, por se tratar de mulher pobre, negra, catadora de lixo e habitante da favela:

Pensei na vida atribulada que eu levo. Cato papel, lavo roupa para dois jovens. Permaneço na rua o dia todo. E estou sempre em falta. A Vera não tem sapatos. E ela não gosta de andar descalça. Faz uns dois anos que eu pretendo comprar uma maquina de moer carne. $\mathrm{E}$ uma maquina de costura (Jesus, 1993, p. 5).

Como destaca Fernanda Miranda (2013, p. 19), na obra de Carolina Maria de Jesus "normalmente mesclam-se as instâncias textuais autora/narradora/personagem, tornando problemática a delimitação rígida os campos do real e da ficção em sua obra". O espaço diegético se confunde com o espaço real e com a própria existência da autora, numa rica tessitura de acontecimentos, visões, experiências e trabalho com a palavra: a palavra catada no lixo e a colocada no papel, de forma que não seria exagero chamar essa escritura de (po)ética, pois produz uma zona de indiscernibilidade entre a ética e o fazer poético. Carolina se inscreve e escreve no texto, reivindicando, a todo tempo, seu direito de narrar, contradizendo as palavras de alguns intelectuais, quando propõem que, sem acesso à instrução formal e aos bens considerados essenciais, como a alimentação adequada, o sujeito "espoliado" não tem acesso à literatura erudita, quanto menos a produzir isso que se chama literatura:

Quando falo com uma criança lhe dirijo palavras agradaveis. O que aborrece-me é elas vir na minha porta para perturbar a minha escassa tranquilidade interior [...] Mesmo elas aborrecendo-me, eu escrevo. Sei dominar meus impulsos. Tenho apenas dois anos de grupo escolar, mas procurei formar o meu carater (Jesus, 1993, p. 13). 
Assim, olhar a obra de Carolina ou de outras autoras e autores de fora dos espaços hegemônicos de enunciação como mero documento sociológico corresponde a obliterar seu direito de narrar e ignorar a dimensão estética de sua escrita, como propõe Miranda (2013), além de privá-los da pertença ao campo literário, privação que a própria Carolina denuncia em sua (po)ética.

O intracolonialismo epistêmico ${ }^{6}$ ainda presente no conjunto de codificações que configura a visão de mundo brasileira, foi responsável por essa privação, movimento que acaba reverberando mesmo no espaço da favela: "Aqui, todas impricam comigo. Dizem que falo muito bem. Que sei atrair os homens. [...] Quando fico nervosa não gosto de discutir. Prefiro escrever. Todos os dias eu escrevo. Sento no quintal e escrevo" (Jesus, 1993, p. 19). A escritura (Derrida, 1967) permite o transbordamento de um mundo codificado, apagando as linhas que separam a existência da literatura. A escrevivência (Evaristo, 2008), por sua vez, permite o transbordamento da memória e sua montagem com a história, penetrando nos espaços em branco do texto. Carolina também escreve sobre seu lugar de não fala: "quando estou na cidade tenho a impressão que estou na sala de visitas com seus lustres de cristais, seus tapetes de viludos, almofadas de sitim. E quando estou na favela tenho a impressão de estar num quarto de despejo" (Jesus, 1993, p. 37). O quarto de despejo é o local da casa onde se colocam todas as coisas "fora de uso". Aquelas que não se quer ver no cotidiano, porque ocupam espaço na casa. E o quarto fica cada vez mais cheio:

29 DE MAIO Até que enfim parou de chover. As nuvens deslisase para o poente. Apenas o frio nos fustiga. E varias pessoas da favela não tem agasalhos. Quando uns tem sapatos, não tem palitol. E eu fico condoída vendo as crianças pisar na lama. [...] Percebi que chegaram novas pessoas para a favela. Estão maltrapilhas e as faces desnutridas. Improvisaram um barracão. Condoí-me de ver tantas agruras reservadas aos proletarios. Fitei a nova companheira de infortunio. Ela olhava a favela, suas lamas e suas crianças pauperrimas. Foi o olhar mais triste que eu já

\footnotetext{
${ }^{6}$ Intracolonialismo epistêmico, em outras palavras, corresponde à repetição de atitudes, métodos e perspectivas colonialistas em uma dimensão micropolítica - como denunciou Spivak ao questionar a univocidade da leitura sobre a subalternidade feita por alguns intelectuais -, que prevê uma perspectiva binária entre opressor/oprimido, e oblitera o lócus de enunciação de grupos dentro de um contexto de subalternidade (no caso específico de Spivak, a mulher na sociedade indiana), e apaga outras possibilidades de entender ou escrever a história.
} 
presenciei. Talvez ela não mais tem ilusão. Entregou sua vida aos cuidados da vida. ...Há de existir alguem que lendo o que eu escrevo dirá... isto é mentira! Mas, as miserias são reais. ...O que eu revolto é contra a ganancia dos homens que espremem uns aos outros como se espremesse uma laranja (Jesus, 1993, p. 41).

Ouvir a perspectiva das vozes apagadas da história é uma maneira de reescrever essa mesma história, é uma maneira de compreendê-la ao mesmo tempo que se produz novas maneiras de existir. Como disse Edward Said, o presente e o passado se moldam mutuamente. É assustador deduzir que os heróis que se constituem também como mitos da história são quase todos homens, brancos e genocidas. Um dos poucos heróis negros do imaginário coletivo brasileiro é Zumbi dos Palmares, mencionado brevemente nos livros de história. Jarid Arraes (2015) enaltece em sua obra a figura de Dandara dos Palmares, figura pouco conhecida, como a autora explica na introdução da obra: "embora muitas pessoas até ouçam falar de Zumbi, líder do quilombo de Palmares e homenageado em 20 de novembro, Dandara ainda permanece esquecida e ignorada" (2005, p. 7). A autora ainda denuncia a dificuldade em encontrar material histórico sobre Dandara:

É possível encontrar na internet alguns artigos que falam de Dandara, a maioria em portais do movimento negro e feminista, mas as informações são bastante resumidas. Um dos poucos fatos que realmente sabemos a respeito de Dandara é que ela foi uma das líderes do quilombo de Palmares, companheira de Zumbi e uma mulher que não se encaixava nos papéis femininos estabelecidos em sua época. Aprendi que ninguém sabia muito bem onde Dandara nasceu e que, pelo que se conta, sua morte aconteceu no momento em que Palmares foi invadido com grande repressão; dizem que, para não ser capturada, Dandara se jogou do alto de uma pedreira, preferindo a morte à escravidão (Arraes, 2015, p 7-8).

Arraes retoma a memória de Dandara em sua obra, amalgamando-a a uma ficção que se constitui, como a obra de Conceição Evaristo e Carolina de Jesus, em uma escrevivência: uma montagem de memória, história, experiência e poética. Ainda que haja uma perspectiva cética acerca da existência real de Dandara como personagem histórica, ela existe ao menos na tradição oral como a presença simbólica e potente de uma história apagada. O nascimento de Dandara, na obra de Arraes, 
amalgama-se à história da violenta diáspora africana, contada pela perspectiva de Iansã:

Iansã passava longos períodos refletindo sobre a situação de África. Revisitava as cenas do passado, assistindo milhares de filhos embarcando forçadamente, como mercadorias, em navios que vinham de lugares longínquos. Via o sofrimento em seus rostos e voava pelo oceano, acompanhando cada momento de tortura profunda. Iansã fechava os olhos quando corpos eram jogados ao mar, sem definir o que mais lhe doía: o destino dos que sobreviviam nos porões dos barcos enquanto viajavam em estado degradante ou os que padeciam no meio do caminho e eram descartados sem rituais e sem respeito [...]. Iansã precisou viajar algumas vezes ao passado até compreender totalmente o que acontecia: quando conseguiu engolir a dor dilacerante que a sufocava ao ver o sofrimento dos seus filhos, atentou-se para as expressões e intenções mais íntimas das pessoas mais claras. Viu em seus corações uma imensa camada de ódio e desprezo, tão profundos que criavam raízes nas veias de seus corpos e agiam como uma erva venenosa em suas mentes. "Eles pensam que são superiores!", concluiu espantada (Arraes, 2015, p. 13).

Ao discutir os terríveis acontecimentos com os demais orixás, Iansã acaba por deduzir a melhor estratégia de luta, que culmina na criação de Dandara: "São todos homens! Homens alvos, homens com vestes diferentes, homens empunhando armas e comandando os navios! Homens! [...] Criarei uma guerreira, filha do meu ser, que libertará seus irmãos e irmãs!" (Arraes, 2015, p. 15). A criação se dá pela convocação de nuvens, ventos e tempestades, e Dandara é levada para "o novo continente aonde os filhos de África haviam sido levados" (Arraes, 2015, p. 17).

Arraes reescreve, assim, o mito fundador da identidade afrobrasileira de maneira não empática à história oficial, por estabelecer um lócus de enunciação que valoriza os elementos da memória, da história oral e das tradições cosmogônicas africanas, como a potência dos orixás e as poucas informações encontradas sobre Dandara.

Aludindo novamente ao texto de Spivak, talvez faça parte do papel dos intelectuais contemporâneos dos países latino-americanos resgatarem esses discursos historicamente silenciados pelos processos colonizatório e imperialista, processos esses que ainda mantêm seus valores entremeados na estruturação dos discursos populares e acadêmicos por meio de um intracolonialismo epistêmico. Permito-me aqui subverter um pouco o 
discurso de Gayatri Spivak já citado neste artigo. Afirmo que no contexto do itinerário obliterado do sujeito feminino, o caminho da diferença racial e espacial é duplamente obliterado. Se no contexto da produção literária o sujeito feminino não tem história e não pode falar, o sujeito feminino negro e periférico está ainda mais profundamente na obscuridade. Sua não pertença aos cânones não tem raiz na ausência de algum aspecto estrutural ou formal, mas unicamente na posição subalterna em que foram historicamente alocadas e que a crítica parece constantemente ratificar, seja por meio da escolha de um discurso alegadamente "apolítico" - e se esquece de que essa própria escolha já é política -, seja por reproduzir o modus operandi colonialista e classificar o "Outro" como primitivo, mantendo o pensamento abissal. Autoras como Carolina de Jesus e Jarid Arraes ferem esse pensamento abissal, explicitando, em suas escrevivências políticas e (po)éticas, os transbordamentos que lhes são próprios: "Não tenho força física, mas as minhas palavras ferem mais do que a espada. E as feridas são incicatrisaveis" (Jesus, 1993, p.43), diz Carolina; " - Não vou ser uma dessas! - Esbravejou olhando para a mata atrás de si. - Estão ouvindo?! Jamais serei uma escrava!" (Arraes, 2015, p. 121), grita Dandara, reescrevendo também a história cosmogônica, com o retorno à Iansã, "até o fim".

\section{Referências}

ARRAES, Jarid (2015). As lendas de Dandara. São Paulo: Edição da autora.

BHABHA, Homi (2014) The right to narrate. Harvard Design Magazine, Cambridge, Summer. On-line. Disponível em: https://goo.gl/3JnEHX. Acesso em: 5 set. 2016.

CANDIDO, Antonio (1988). Direito à literatura. In: CANDIDO, Antonio. Vários escritos. Rio de Janeiro: Ouro sobre Azul.

CANDIDO, Antonio (2000). Formação da literatura brasileira: momentos decisivos. 6. ed. Belo Horizonte: Itatiaia.

DELEUZE, Gilles (1992). Conversações. São Paulo: 34.

DERRIDA, Jacques (1967). A escritura e a diferença. São Paulo: Perspectiva.

DERRIDA, Jacques (1973). Gramatologia. São Paulo: Perspectiva. 
EVARISTO, Conceição (2008). Escrevivências da afro-brasilidade: história e memória. Releitura, Belo Horizonte, n. 23.

EVARISTO, Conceição (2015). Olhos d'água. Rio de Janeiro: Pallas.

FOUCAULT, Michel (1979). Microfísica do poder. Rio de Janeiro: Graal.

GRAMSCI, Antonio (1999-2002). Cadernos do cárcere. Rio de Janeiro, Civilização Brasileira. $6 \mathrm{v}$.

JESUS, Carolina Maria de (1993). Quarto de despejo: diário de uma favelada. São Paulo: Ática.

JESUS, Carolina Maria de (1996). Antologia pessoal. Rio de Janeiro: Editora da UFRJ.

MIRANDA, Fernanda (2013). Os caminhos literários de Carolina Maria de Jesus: experiência marginal e construção estética. Dissertação (Mestrado em Letras) Universidade de São Paulo, São Paulo.

PAZ, Octavio (2014). O arco e a lira. São Paulo: Cosac Naify.

SAID, Edward (2007). Orientalismo: o oriente como invenção do ocidente. São Paulo: Companhia das Letras.

SAID, Edward (1995). Cultura e imperialismo. São Paulo: Companhia das Letras.

SANTOS, Boaventura de Sousa (2007). Para além do pensamento abissal: das linhas globais a uma ecologia de saberes. Coimbra: Centro de Estudos Sociais.

SANTOS, Boaventura de Sousa (1997). Uma concepção multicultural de direitos humanos. Lua Nova, São Paulo, n. 39, p. 105-201.

SPIVAK, Gayatri Chakravorty (2010). Pode o subalterno falar? Belo Horizonte: Editora da UFMG.

Recebido em 7 de novembro de 2016.

Aprovado em 26 de janeiro de 2017.

\section{resumo/abstract/resumen}

\section{(Po)éticas da escrevivência}

\section{Luana Barossi}

O presente ensaio tem como foco a discussão sobre alguns loci de enunciação mantidos pela crítica literária em uma posição subalterna ao serem proscritos do 
campo literário. A perspectiva teórica enfoca as noções de direito à literatura, de Antonio Candido, a (im)possibilidade de enunciação do subalterno, de Gayatri Spivak, o direito de narrar, de Homi Bhabha e o conceito de escrevivência, de Conceição Evaristo.

Palavras-chave: literatura afro-brasileira, ética, subalternidade, escrevivência, pós-colonial.

\section{(Po)ethics of escrevivência}

\section{Luana Barossi}

This paper focuses on the discussion of certain loci of enunciation that literary critics maintain in a subaltern position by locating them outside the literary field. The article approaches this theme through the concepts of the right to literature, by Antonio Candido, the subaltern's (im)possibility of enunciation, as proposed by Gayatri Spivak, the right to narrate, by Homi Bhabha, and, finally, the notion of escrevivência, by Conceição Evaristo.

Keywords: Afro-Brazilian literature, ethics, subaltern, escrevivência, postcolonialism.

\section{(Po)éticas de la escrevivencia}

\section{Luana Barossi}

El presente ensayo se centra en la discusión acerca de algunos los lugares de enunciación mantenidos por la crítica literaria en una posición subalterna una vez que son marginalizados en el campo literario. La perspectiva teórica se centra en las nociones de derecho a la literatura, de Antonio Candido, la (im)posibilidad de enunciación de lo subalterno, de Gayatri Spivak, el derecho de narrar, de Homi Bhabha, y la escrevivência, de Conceição Evaristo.

Palabras clave: literatura afrobrasileña, ética, subalternidad, escrevivência, póscolonial. 